\title{
OPTIMALISASI PENGELOLAAN KAS DAN MANAJEMEN \\ KEUANGAN YANG PROFESIONAL DALAM PENGEMBANGAN BISNIS DI ERA KOMPETITIF PADA KOMUNITAS XBANK TANGERANG
}

\author{
Aidil Amin Effendy ${ }^{1}$, Mahnun Mas'adi², Widhi Wicaksono ${ }^{3}$, Ahmad Nurhadi ${ }^{4}$, \\ Heri Murtiyoko 5 \\ Universitas Pamulang \\ aidi100967@unpam.ac.id
}

\begin{abstract}
Cash management is the most important part of the financial arrangement of a business, especially a micro business. Cash management can be defined as the management of money owned by a business actor in order to achieve optimal cash availability. cash management is a system in the financial management of business actors specifically in cash flow. Cash is one of the most liquid assets (the most current), which can be used immediately to meet the financial obligations of a business. The purpose of Community Service (PKM) is to optimize cash management and financial management for micro-entrepreneurs in the Xbank Tangerang Selatan Community. The method used in community service is in the form of verbal delivery of material through zoom media, how to make structured notes according to accounting principles and more modern and measurable records with reports that are easy to understand. As well as guiding until these entrepreneurs can really succeed in their application. As well as providing solutions provided to guidance partners on how to perform cash management and financial management optimally, measurable and structured, in order to separate risk and income, neatly and professionally. The result of community service obtained is an increase in knowledge and adequate insight into cash management and professional financial management which is believed to be able to develop SMEs and be more professional. Providing consultative guidance in carrying out cash management and financial management optimally, as well as providing guidance on how to perform cash management and financial management optimally, measurable and structured, in order to separate risk and income, neatly and professionally.
\end{abstract}

Keywords: XBank community, UKM players, science, cash registers 


\section{Abstrak}

Pengelolaan kas merupakan bagian terpenting dalam penataan keuangan suatu usaha, apalagi usaha mikro. Manajemen kas dapat diartikan sebagai pengelolaan uang yang dimiliki pelaku usaha dalam rangka pencapaian tersedianya kas yang optimal. Manajemen kas adalah sistem pada pengaturan keuangan pelaku usaha yang khusus dalam arus kas. Kas merupakan salah satu bagian dari aktiva yang paling likuid (paling lancar), yang bisa dipergunakan segera untuk memenuhi kewajiban finansial suatu usaha. Adapun tujuan dari Pengabdian kepada Masyarakat (PKM) ini adalah untuk mengoptimalkan pengelolaan kas dan manajemen keuangan pada para pengusaha mikro Komunitas XBank Tangerang Selatan. Metode yang digunakan pada Pengabdian masyarakat ini berupa penyampaian materi secara verbal melalui media zoom cara membuat pencatatan yang terstruktur sesuai kaidah Akuntansi dan pencatatan yang lebih modern dan terukur dengan laporan yang mudah dipahami. Serta membimbing sampai para pengusaha tersebut benar-benar dapat berhasil pada penerapanya. Serta memberikan solusi yang diberikan kepada mitra bimbingan bagaimana cara melakuan pengelolaan kas dan manajemen keuangan secara optimal terukur dan terstruktur, agar dapat memisahkan resiko dan pendapatan, secara rapi dan profesional. Hasil pengabdian masyarakat yang diperoleh adalah bertambahnya ilmu pengetahuan dan wawasan yang memadai mengenai pengelolaan kas dan menajemen keuangan secara profesional yang diyakini dapat mengembangkan UKM dan lebih profesional. Pemberian bimbingan konsultatif dalam melakukan pengelolaan kas dan manajemen keuangan secara optimal, serta memberikan bimbingan bagaimana cara melakuan pengelolaan kas dan manajemen keuangan secara optimal terukur dan terstruktur, agar dapat memisahkan resiko dan pendapatan, secara rapi dan profesional.

Kata Kunci : Komunitas XBank, Pelaku UKM, Ilmu Pengetahuan, Pencatatan Kas

\section{A. PENDAHULUAN}

UKM adalah bentuk usaha mikro, kecil menengah yang ada di kalangan masyarakat dimana usaha ini didirikan berdasarkan inisiatif seseorang. Sebagian besar opini yang ada dikalangan masyarakat menganggap bahwa UKM hanya dapat menguntungkan pihak-pihak tertentu saja. Padahal UKM juga dapat berperan membantu pemerintah dalam mengurangi tingkat pengangguran yang ada di Indonesia. UKM di Indonesia mampu menyerap banyak tenaga kerja Indonesia yang masih belum mempunyai pekerjaan atau mengganggur. Selain itu, UKM telah berkontribusi besar dalam meningkatkan pendapatan daerah maupun pendapatan negara Indonesia. UKM dapat memanfaatkan berbagai Sumber Daya Alam yang berpotensial di daerahnyayang belum diolah secara komersial sehigga UKM dapat berkontribusi dan membantu mengolah Sumber Daya Alam yang ada di daerah dimana UKM 
itu berada. Hal ini dapat berkontribusi besar terhadap peningkatan pendapatan daerah maupun pendapatan Negara

Permasalahan di bidang keuangan menjadi salah satu masalah yang paling krusial yang sering terjadi pada UKM di Indonesia. Hal ini disebabkan oleh pemilik UKM yang tidak memiliki kemampuan dalam mengelola keuangan sehingga banyak UKM di Indonesia yang tidak memiliki pembukuan yang rapih dan jelas. Meskipun pembukuan dapat dibuat dengan sangat sederhana, asal pembukuan tersebut rapih dan jelas maka pembukuan itu akan sangat membantu kita dalam mengatur keuangan UKM. Seperti dalam data BPS Kota Tangerang Selatan jumlah UKM di Tangerang Selatan pada tahun 2018 terdapat sejumlah 9.582 unit UKM. Jumlah yang masih sedikit bila dibandingkan dengan Kota Tangerang yaitu sejumlah 11.746 unit pelaku UKM.

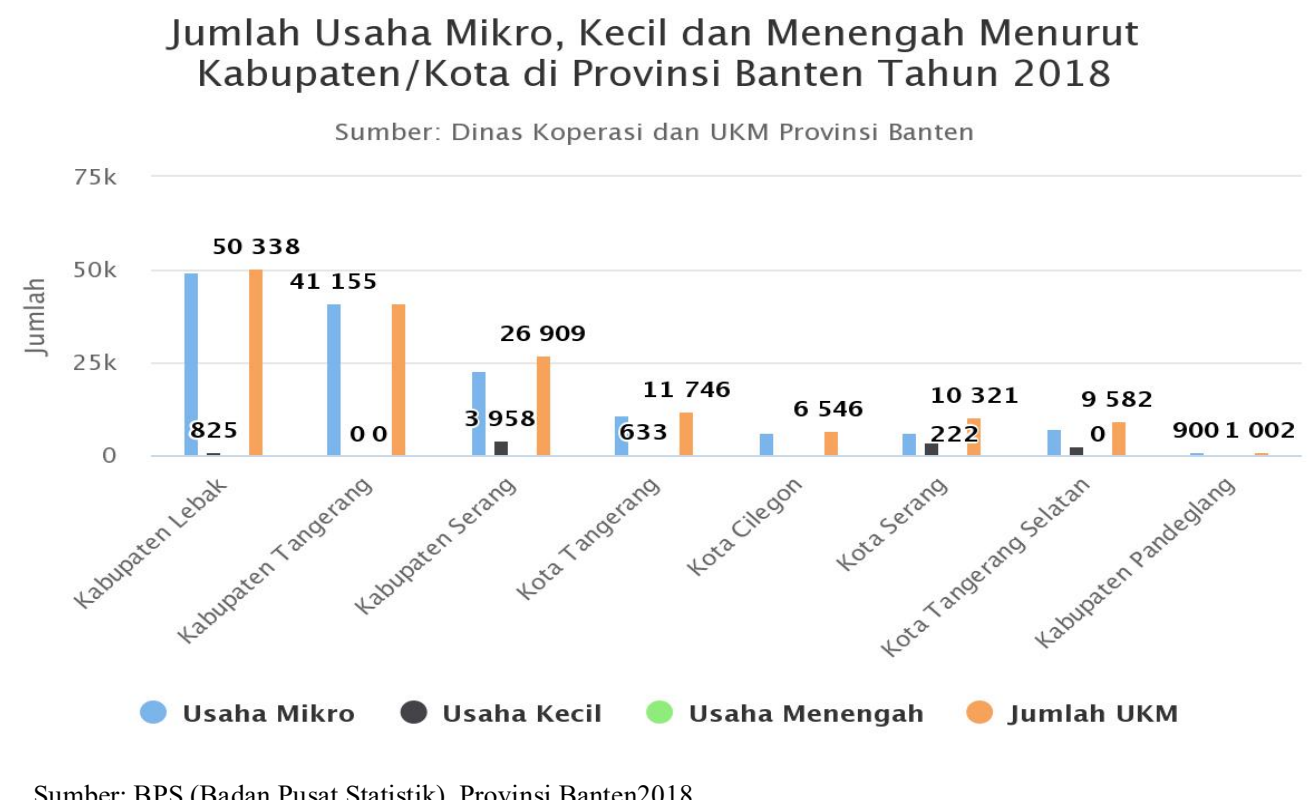

Gambar 1. Jumlah Usaha Mikro, Kecil dan Menengah

Dari data tersebut di atas, sudah seharusnya seluruh elemen masyarakat termasuk dosen dapat ikut serta mewujudkan masyarakat yang mampu mendirikan UKM yang unggul serta berperan dalam kemajuan bangsa dan negara. Dari penelitian yang dilakukan Dadang Suhendar dan Dadang Suhardi (2018) kepada Usaha Kecil Menengah (UKM) kerupuk Dorokdok Desa Cibingbin, Kecamatan Cibingbin, Kabupaten Kuningan, timbul "permasalahan di bidang keuangan menjadi salah satu masalah yang paling krusial yang sering terjadi pada UKM di Indonesia. Hal ini disebabkan oleh pemilik UKM yang tidak memiliki kemampuan dalam mengelola keuangan sehingga banyak UKM di Indonesia yang tidak memiliki pembukuan yang rapih dan jelas".

Dari penelitian tersebut, harusnya menjadi intropeksi dan evaluasi karena dalam mendirikan usaha haruslah mempunyai bekal ilmu dan keterampilan dalam membuat dan menggunakan pembukuan sederhana. Pembukuan juga dianggap mempunyai peran yang sangat penting yang digunakan untuk mengetahui berapa keuntungan dan kerugian yang kita perolehberwirausaha agar usaha yang dijalankan dapat berjalan dengan baik dan menghasilkan laba yang optimal. Oleh karena itu, "Manajemen kas perlu dilakukanperusahaan untuk terus menjaga keberadaan dan keberlangsungannya. Kaslaksana 
darah dalam tubuh kita. Jika aliran darah terganggu, maka akan mempengaruhi kesehatan tubuh" (Jamaludin et al. 2020).

Oleh karena itu, para pengusaha dari Xbank perlu dibuatkan terobosan dalam pengelolaan kas usahanya, agar pembukuan tercatat lebih rapi, dan professional. Dan juga dapat memberikan keuntungan yang lebih daripada sebelumnya. Dalam pengabdian kepada masyarakat (PKM) yang dilakukan oleh dosen-dosen UNPAM khsusnya dosen Manajemen Fakultas Ekonomi ini salah satu upaya dalam membekali dan memberikan ilmu pengetahuan tentang pengelolaan kas. Tema PKM kali ini adalah "Optimalisasi Pengelolaan Kas dan Manajemen Keuangan yang Profeisonal Dalam Pengembangan Bisnis di Era Kompetitif”.

\section{B. METODE PELAKSANAAN KEGIATAN}

Metode Pelaksanaan Pengabdian Masyarakat ini di antaranya : Tahap Pertama yaitu Pemberian materi optimalisasi pengelolaan Kas dalam pengembangan bisnis di era kompetitif Dalam memberikan materi optimalisasi pengelolaan Kas ini, akan dibahas bagaimana caranya membuat pencatatan yang terstruktur sesuai kaidah Akuntansi dan pencatatan yang lebih modern, hal ini agar pihak mitra yaitu pengusaha agar dapat terarah dan terprogram dalam mengelola Kas dan manajemen keuangan secara Optimal agar usahanya lebih profeisonal dan berkembang.

Adapun Prof. Dr. S. Nasution (2015:26) berpendapat mengenai "Ciri-ciri Belajar yang ditinjau berdasarkan sumber yaitu diantaranya memanfaatkan sepenuhnya segala sumber informasi sebagai sumber bagi pelajaran termasuk alat-alat audio-visual dan memberi kesempatan untuk merencanakan kegiatan belajar dengan mempertimbangkan sumbersumber yang tersedia." Dalam pemberian materi pembukuan dan manajemen keuangan oleh dosen-dosen menggunakan alat bantu berupa zoom dikarenakan masih dalam masa pandemic Covid 19 agar peserta lebih fokus dalam mengikuti penyuluhan seperti gambar di bawah ini.

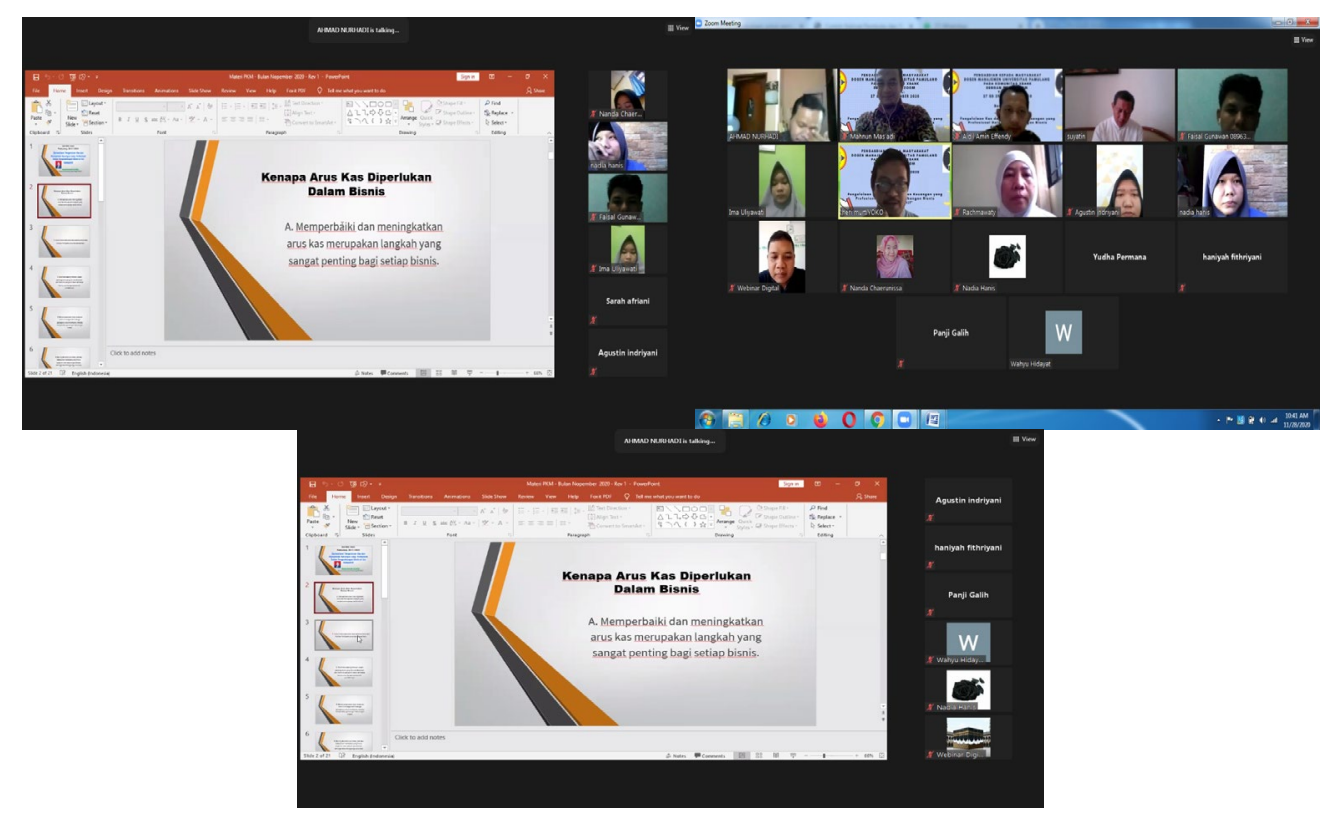

Gambar 2. Tim PKM Dosen Universitas Pamulang sedang memberikan materi 
Tahap kedua yaitu : Diskusi, Tanya Jawab dan Bimbingan konsultatif dalam melakukan pengelolaan kas dan manajemen keuangan secara optimal. Solusi yang diberikan kepada mitra bimbingan bagaimana cara melakuan pengelolaan kas dan manajemen keuangan secara optimal terukur dan terstruktur, agar dapat memisahkan resiko dan pendapatan, secara rapi dan professional dalam menjalankan bisnis. Kegiatan diadakan pada Komunitas XBank Tangerang Selatan selama 3 hari yaitu pada tanggal 27, 28 dan 29 November 2020 melalui Video Conference dengan aplikasi Zoom.

\section{HASIL DAN PEMBAHASAN}

Hasil dari pemberian materi manajemen keuangan dan pembukuan kas oleh dosen Manajemen Universitas Pamulang dan simulasi pembelajaran pembuatan laporan keuangan dan bimbingan sampai para pengusaha tersebut benar-benar dapat berhasil pada penerapanya nanti. Selain pemberian materi dan simulasi, tim PKM juga mengadakan praktek dan bimbingan cara membuat laoran kas dan manajemen keuangan secara sederhana, karena para pelaku UKM saat ini sudah sepatutnya mempunyai keilmuan, keterampilan dan wawasan mengenai pencatatan laporan keuangan walau sederhana, karena era dan zamannya sudah online dan luar negeri sudah menjamur di masyarakat, sehingga generasi wirausaha muda harus selalu siap bersaing dengan produk luar negeri yang sudah mnguasai produk di dalam negeri. Hasil pengabdian masyarakat yang diperoleh adalah bertambahnya keilmuan pelaku UKM Komunitas XBank dalam melakuan pengelolaan kas dan manajemen keuangan secara optimal terukur dan terstruktur, agar dapat memisahkan resiko dan pendapatan, secara rapi dan professional.

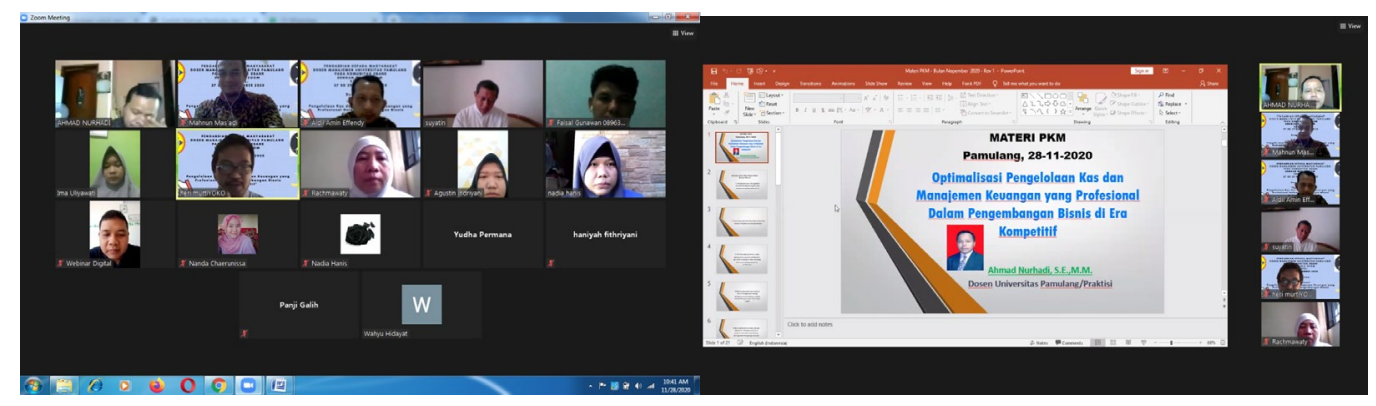

\section{Gambar 2 Pembukaan oleh Tim PKM Gambar 3. Pemberian Materi PKM}

Kegiatan pada gambar di atas pembukaan dan doa agar seluruh rangkaian kegiatan PKM dapat berjalan lancar, yang dilanjutkan dengan mengadakan ice breaking sebelum pemberian materi keuangan agar peserta lebih fokus dalam mengikuti penyuluhan yang dilakukan dosendosen Fakultas Ekonomi Universitas Pamulang.

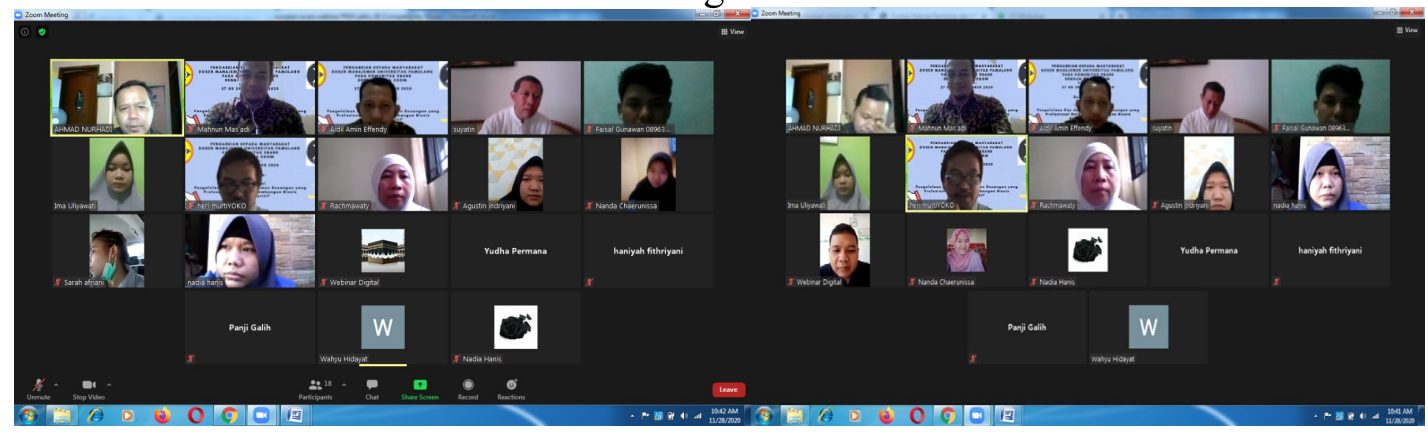

Gambar 4. Sesi Diskusi dan Tanya Jawab bersama Pelaku UKM Komunitas XBank Tangerang yang bertanya dan menjawab kuis dari Tim PKM Dosen Universitas Pamulang 
Adapun gambar di atas yaitu diskusi dan tanya jawab antara peserta kepada Tim PKM, kemudian Tim PKM yang merupakan dosen-dosen Unpam menanggapi dan menjawab pertanyaan yang diajukan oleh para peserta

\section{KESIMPULAN DAN SARAN}

Hasil dari Pelaksanaan kegiatan PKM oleh dosen-dosen Fakultas Ekonomi Universitas Pamulang dapat membuahkan hasil yang positif terlihat dari antusias dan bersemangat dalam mengikuti pemberian materi, tanya jawab dan kuis.

Saran kami bagi pelaku UKM Komunitas XBank untuk dapat bertambahnya keilmuan pelaku UKM Komunitas XBank dalam melakuan pengelolaan kas dan manajemen keuangan secara optimal terukur dan terstruktur, agar dapat memisahkan resiko dan pendapatan, secara rapi dan professional. Kami berharap kegiatan pengabdian kepada masyarakat di masa yang akan datang dapat lebih terprogram dan terlaksana dengan baik. Semoga kegiatan pengabdian masyarakat ini dapat bermanfaat bagi masyarakat, khususnya Komunitas XBank Tangerang

\section{DAFTAR PUSTAKA}

Ardiana, I.D.K.R., Brahmayanti, L.A. dan Subaedi. 2010. "Kompetensi SDM UKM dan Pengaruhnya Terhadap Kinerja UKM di Surabaya." Jurnal Manajemen dan Kewirausahaan, 12 (1)

Djamarah, Syaiful Bahri dan Aswan Zain. 2014. "Strategi Belajar Mengajar.” Cet 5, PT Rineka Cipta, Jakarta.

Effendy, A. A., Budiyanto, A., Nurhadi, A., Murtiyoko, H., \& Mas'adi, M. (2020). "Implementasi Kewirausahaan dan Koperasi di Sekolah pada SMK Mulia Buana, Parung Panjang-Kab. Bogor.” DEDIKASI PKM, 1(2), 105-110.

Effendy, A. A., Mas'adi, M., Wicaksono, W., Nurhadi, A., \& Murtiyoko, H. (2020). "Mewujudkan Generasi Muda Yang Unggul Di Era Globalisasi Dengan Berbekal Ilmu Wirausaha Yang Kreatif, Inovatif Dan Diferensiatif Pada Remaja Masjid Al Hikmah Reni Jaya Pamulang Tangerang Selatan.” Jurnal Pengabdian Dharma Laksana, 3(1), 815.

Effendy, A. A., Sudarso, A. P., Nurhadi, A., Arifianto, C. F., \& Kartono, K. (2020). "Peningkatan Profesionalisme Guru Dan Pengembangan Sdm Dalam Menghadapi Era Revolusi Industri 4.0 Pada Guru SMK Mulia Buana Parung Panjang Bogor.” Abdi Laksana, 1(2).

Jamaludin, J., Sutiman, S., \& Thaharuddin, T. (2020). “Optimalisasi Pengelolaan Kas Dalam Meminimalkan Kerugian Dan Meningkatkan Profit Usaha Mikro Ibu-Ibu PKK Di Kelurahan Rempoa, Kecamatan Ciputat Timur, Kota Tangerang Selatan.” Jurnal ABDIMAS Tri Dharma Manajemen, 1(3), 17-27.

Nasution, Prof. Dr. S., 2015. "Berbagai Pendekatan dalam Proses Belajar dan Mengajar”, PT Bumi Aksara, Jakarta

Suhendar, D., \& Suhardi, D. (2018). “Optimalisasi Pengelolaan Usaha Kecil Menengah (UKM) Kerupuk Dorokdok Desa Cibingbin Kecamatan Cibingbin, Kabupaten Kuningan. Empowerment.” Jurnal Pengabdian Masyarakat, 1(02). 
Sunarsi, D., \& Asmalah, L. (2018). "Pelatihan Manajemen Pengembangan Diri Bagi Penerima Beasiswa RZIS UGM dan Dompet Shalahuddin Jogjakarta." Jurnal Pengabdian Dharma Laksana, 1(1).

Suryana. 2004. "Modul Kewirausahaan SMK." Jakarta, Direktorat Pendidikan Menengah Kejuruan, Departemen Pendidikan Nasional.

Vivathuvahna, A.A. dan Nugroho, T.R.D.A. 2015. "Intensi Kewirausahaan Mahasiswa Universitas Trunojoyo Madura.” Jurnal Agriekonomika, 4 (1). 